\title{
Beraprost sodium, a stable prostacyclin analogue, improves insulin resistance in high-fat diet-induced obese mice
}

\author{
Eriko Inoue ${ }^{1}$, Toshihiro Ichiki ${ }^{1,2}$, Kotaro Takeda ${ }^{1,2}$, Hirohide Matsuura ${ }^{1}$, Toru Hashimoto ${ }^{1}$, Jiro Ikeda ${ }^{1}$, \\ Aya Kamiharaguchi ${ }^{1}$ and Kenji Sunagawa ${ }^{1}$ \\ Departments of ${ }^{1}$ Cardiovascular Medicine and ${ }^{2}$ Advanced Therapeutics for Cardiovascular Diseases, Kyushu University Graduate School of Medical Sciences, \\ Fukuoka, Japan \\ (Correspondence should be addressed to T Ichiki at Department of Advanced Therapeutics for Cardiovascular Diseases, Kyushu University Graduate School of \\ Medical Sciences; Email: ichiki@cardiol.med.kyushu-u.ac.jp)
}

\begin{abstract}
Obesity induces hypertrophy of adipocyte resulting in production of pro-inflammatory cytokines such as tumor necrosis factor- $\alpha$ (TNF- $\alpha$ ) and monocyte chemoattractant protein 1 (MCP1 (CCL2)). These cytokines play an important role in the development of insulin resistance. Beraprost sodium (BPS), a prostaglandin $\mathrm{I}_{2}$ analogue, is reported to attenuate inflammation. In this study, we examined the effect of BPS on glucose metabolism in mice fed a high-fat diet (HFD). Four-week-old C57/B6 male mice were fed a HFD for 12 weeks (HFD group) and the treatment group received oral BPS ( $300 \mu \mathrm{g} / \mathrm{kg}$ per day) for the same period. Then, glucose metabolism, histological changes, and gene expression of white adipose tissue (WAT) were examined. Body weight was increased, and glucose
\end{abstract}

intolerance and insulin resistance were developed in the HFD group. Treatment with BPS improved glucose tolerance and insulin action without body weight change. Histological analysis of WAT showed an increase in the size of adipocyte and macrophage infiltration in the HFD group, which was attenuated by BPS treatment. BPS reduced HFD-induced expression of MCP1 and TNF- $\alpha$ in WAT. BPS also attenuated hepatic steatosis induced by the HFD. These results suggest that BPS improved glucose intolerance possibly through suppression of inflammatory cytokines in WAT. BPS may be beneficial for the treatment of obesity-associated glucose intolerance.

Journal of Endocrinology (2012) 213, 285-291

\section{Introduction}

Obesity plays a central role in the development of metabolic syndrome (Wajchenberg 2000), a constellation of risk factors such as insulin resistance, dyslipidemia, and high blood pressure. Accumulation of visceral fat rather than subcutaneous fat is believed to cause insulin resistance (Wajchenberg 2000, Masuzaki et al. 2001). In obesity, adipocytes are enlarged and increased in number, and an excess of lipid leads to ectopic deposition of triglyceride in the liver and muscle, which is one of the causes of insulin resistance (Savage et al. 2007). The hypertrophied adipocytes produce proinflammatory cytokines such as monocyte chemoattractant protein-1 (MCP1 (CCL2)) and tumor necrosis factor- $\alpha$ (TNF- $\alpha$ ) as obesity progresses (Shoelson et al. 2006). These cytokines, so-called adipokines, cause inflammation and recruitment of macrophages to adipose tissue (Xu et al. 2003), which is another important mechanism for obesity-induced insulin resistance. The infiltrated macrophages enhance inflammation of adipose tissue, indicating that these processes form a vicious circle.

TNF- $\alpha$ induces $c-J u n$ amino-terminal kinase (JNK) activation and phosphorylation of insulin receptor substrate 1 (IRS1) at serine residues that negatively regulate normal signaling through the insulin receptor/IRS1 axis (Hotamisligil et al. 1996). Mice lacking chemokine receptor-2 (CCR2), a receptor for MCP1, are partly protected against developing high-fat diet (HFD)-induced insulin resistance and exhibit reductions in adipose tissue macrophage recruitment and inflammatory gene expression (Weisberg et al. 2006). These observations suggest that adipose tissue in obesity is characterized by chronic low-grade inflammation, and inflammatory cytokines play a causative role in the development of insulin resistance.

Beraprost sodium (BPS) is a stable prostaglandin $I_{2}$ analogue and has a potent vasodilating effect through activation of prostacyclin receptor (Olschewski et al. 2004). BPS is also reported to attenuate inflammation. BPS reduced serum TNF- $\alpha$ levels in diabetic patients (Fujiwara et al. 2004) and expression of Mcp 1 mRNA in the kidney of Otsuka Long-Evans Tokushima fatty (OLETF) rats, resulting in the amelioration of diabetic nephropathy (Watanabe et al. 2009). BPS inhibits 
TNF- $\alpha$-induced expression of vascular cell adhesion molecule and monocyte attachment to endothelial cells (Goya et al. 2003). We therefore hypothesized that the anti-inflammatory effects of BPS may be beneficial for the improvement of obesity-induced insulin resistance, in which inflammation plays an important role.

We showed in this study that BPS improved glucose metabolism in association with reduction of inflammation of white adipose tissue (WAT) in a mouse model of dietinduced obesity.

\section{Materials and Methods}

\section{Animals}

All procedures were approved by the institutional animal use and care committee and were conducted in conformity with institutional guidelines. Four-week-old C57/B6 mice were purchased from Kyudo Co. Ltd. (Tosu, Saga, Japan). Three groups were analyzed: mice fed a normal chow diet (control group), mice fed a HFD containing 60\% kcal fat (High Fat Diet 32, Clea Japan (Tokyo); HFD group) for 12 weeks, and mice fed a HFD and administered BPS for 12 weeks (BPS group). BPS dissolved in water at $1.5 \mu \mathrm{g} / \mathrm{ml}$ was given ad libitum because of the short half-life of BPS $(\sim 1 \mathrm{~h})$. As a preliminary study showed that the estimated volume of water intake was $\sim 0.2 \mathrm{ml} / \mathrm{g}$ per day, the estimated dose of orally ingested BPS was $300 \mu \mathrm{g} / \mathrm{kg}$ per day. At the end of the experiment, systolic blood pressure (SBP) and heart rate (HR) were measured by a tail-cuff method (BP-98A, Softron Co., Tokyo, Japan). Mice were killed by $\mathrm{CO}_{2}$ inhalation.

\section{Histological analysis}

Adipose tissues were fixed with $10 \%$ formaldehyde for $24 \mathrm{~h}$. The specimens were embedded into paraffin. Paraffin sections were stained with hematoxylin and eosin (H\&E). The cross-sectional area for each adipocyte was determined using Dynamic cell count BZ-HIC (Keyence, Osaka, Japan). To detect macrophage infiltration, the paraffin sections were stained with an antimouse MAC3 (LAMP2) antibody (Santa Cruz Biotechnology, Inc., Santa Cruz, CA, USA). Sections were deparaffinized with xylene and refixed with ethanol for $40 \mathrm{~min}$, immersed in PBS, and then autoclaved in citrate buffer for antigen retrieval. Then, the sections were incubated with 3\% hydrogen peroxide in methanol for $20 \mathrm{~min}$. The sections were further incubated with an antibody against MAC3 (1:200) overnight at $4{ }^{\circ} \mathrm{C}$. After rinsing with PBS, the sections were incubated with biotin-labeled goat anti-rabbit IgG antiserum (Santa Cruz Biotechnology, Inc., 1:200 dilution) for $30 \mathrm{~min}$ and then incubated with avidin-biotin complex (Vectastain ABC kit; 1:100 dilution) for $15 \mathrm{~min}$, and the sections were incubated with 3,3-diaminobenzidine and $0.03 \%$ hydrogen peroxide in deionized water for about $80 \mathrm{~s}$. The number of MAC3-positive cell clusters was counted in high power field (HPF). The data are mean of five randomly chosen HPFs. After the mice were killed, the livers were removed and subsequently fixed in $10 \%$ formaldehyde. The sections were embedded in paraffin blocks and stained with H\&E to examine the structures of the liver and evaluate lipid droplets. For the quantification of areas of lipid accumulation in the liver, H\&E-stained images of liver were uploaded into a computer for analysis. The images were processed into two gradations (black and white). The white porosity areas were quantified as vacuolation (Sato et al. 2010), which mostly represents accumulation of lipid droplets. Contribution of arteries, veins, and bile ducts to porosity area was small and equally observed in the three groups and therefore ignored in the quantification. The data are expressed as a percentage of white area to total area.

\section{Glucose tolerance test and insulin tolerance test}

Mice were starved for $6 \mathrm{~h}$. Then, the mice were i.p. injected with glucose $(1 \mathrm{~g} / \mathrm{kg}$ of body weight) for the glucose tolerance test (GTT). For the insulin tolerance test (ITT), the mice were i.p. injected with rapid insulin $(0.5 \mathrm{IU} / \mathrm{kg}$ of body weight). Blood was taken from tail vein at various time points to measure blood glucose concentrations by Glutest Every (Sanwa Kagaku Kenkyusho, Nagoya, Japan).

\section{Measurement of serum levels of triglyceride, cholesterol, and insulin}

Serum triglyceride and total cholesterol levels were determined by commercially available kits, Triglyceride E-test Wako (Wako, Osaka, Japan) and Cholesterol E-test Wako (Wako) respectively. Serum insulin levels were determined by ELISA kit (Morinaga Institute of Biological Science, Yokohama, Japan).

\section{$R N A$ extraction and real-time quantitative $R T-P C R$ analysis}

RNA from adipose tissue was extracted using ISOGEN according to the manufacturer's instruction (Wako). One microgram of total RNA was reverse transcribed using ReverTra Ace qPCR RT Kit (Toyobo, Osaka, Japan). Real-time quantitative PCR (qPCR) was performed using 7500 realtime PCR system (Applied Biosystems) and SYBER Green PCR Master Mix (Applied Biosystems). Primer sequences for real-time qPCR used in this study are as follows:

TNF- $\alpha$ : 5'-AAGCCTGTAGCCCACGTCGTA-3'; 5'-GGCACCACTAGTTGGTTGTCTTTG-3'.

MCP1: 5'-TTAACGCCCCCACTCACCTGCTG-3'; 5'-GCTTCTTTGGGACACCTGCTGC-3'.

$\operatorname{PPAR} \gamma(\operatorname{PPARG})$ :

5'-TGTCGGTTTCAGAAGTGCCTTG-3'; 5'-TTCAGCTGGTCGATATCACTGGAG-3'.

C/EBP $\alpha$ : 5'-TTGAAGCACAATCGATCCATCC-3'; $5^{\prime}$-GCACACTGCCATTGCACAAG-3'.

Adiponectin: 5'-GTCAGTGGATCTGACGACACCAA-3'; $5^{\prime}$-ATGCCTGCCATCCAACCTG-3'.

$18 S$ rRNA: $5^{\prime}$-ACTCAACACGGGAAACCTCA-3 ${ }^{\prime}$; $5^{\prime}$-AACCAGACAAATCGCTCCAC-3'. 
The expression of each gene was normalized with that of $18 s$ rRNA.

\section{ELISA}

ELISA for adiponectin and TNF- $\alpha$ was performed using commercially available kits (R\&D systems, Inc., Minneapolis, $\mathrm{MN}, \mathrm{USA}$ ) in accordance with the manufacturer's instructions.

\section{Statistical analysis}

Statistical analysis was performed with one-way ANOVA and Fisher's test if appropriate. Data are shown as mean \pm s.E.M. $P<0 \cdot 05$ was considered to be statistically significant.

\section{Results}

\section{Hemodynamic and metabolic parameters}

Body weight was significantly increased in the HFD group compared with the control group at the end of the experiment. However, there was no significant difference between the HFD and BPS groups (Table 1). SBP was significantly increased in the HFD group compared with the control group. BPS significantly reduced SBP, but SBP in the BPS group was still significantly higher than that in control group (Table 1). HR was significantly increased in the HFD group compared with the control group. BPS reduced HR, but the difference was not statistically significant (Table 1).

After $16 \mathrm{~h}$ of fasting, lipid profile and glucose and insulin levels were determined. Total cholesterol and triglyceride were significantly increased by the HFD (Table 2). BPS treatment modestly decreased total cholesterol and triglyceride levels. However, the differences were not statistically significant. Fasting insulin and glucose levels were elevated in the HFD group.

\section{BPS improved GTT and ITT}

At the end of experiment, GTTs and ITTs were performed. The HFD group developed glucose intolerance (Fig. 1A) and insulin resistance (Fig. 1C). Treatment of mice with BPS significantly improved glucose tolerance and insulin action (Fig. 1A and C). Interestingly, the basal glucose level was

Table 1 BW, SBP, and HR

\begin{tabular}{|c|c|c|c|}
\hline & BW (g) & $\mathbf{S B P}(\mathrm{mmHg})$ & $\mathbf{H R}$ (b.p.m.) \\
\hline Control $(n=5)$ & $26 \cdot 9 \pm 0 \cdot 5$ & $97 \pm 3$ & $448 \pm 31$ \\
\hline $\operatorname{HFD}(n=10)$ & $43 \cdot 4 \pm 1 \cdot 1^{\dagger}$ & $114 \pm 2^{+}$ & $532 \pm 15^{+}$ \\
\hline $\begin{array}{c}\mathrm{HFD}+\mathrm{BPS} \\
\quad(n=10)\end{array}$ & $43 \cdot 9 \pm 0 \cdot 9^{+}$ & $106 \pm 2^{* \neq}$ & $496 \pm 15$ \\
\hline
\end{tabular}

HFD, high-fat diet; BPS, beraprost sodium; BW, body weight; SBP, systolic blood pressure; HR, heart rate. ${ }^{*} P<0 \cdot 05,{ }^{\dagger} P<0 \cdot 01$ vs control. ${ }^{\ddagger} P<0 \cdot 05$ vs HFD group.
Table 2 Fasting serum chemistry of control, HFD-, and BPS-treated mice

\begin{tabular}{|c|c|c|c|c|}
\hline & $\begin{array}{l}\text { TC } \\
\quad(\mathrm{mg} / \mathrm{ml})\end{array}$ & $\begin{array}{l}\text { TG } \\
\quad(\mathrm{mg} / \mathrm{ml})\end{array}$ & $\begin{array}{l}\text { Insulin } \\
\qquad(\mathrm{ng} / \mathrm{ml})\end{array}$ & $\begin{array}{l}\text { Glucose } \\
\qquad(\mathrm{mg} / \mathrm{ml})\end{array}$ \\
\hline $\begin{array}{l}\text { Control } \\
\quad(n=5)\end{array}$ & $55 \pm 4$ & $66 \pm 12$ & $0 \cdot 16 \pm 0 \cdot 05$ & $59 \cdot 6 \pm 2 \cdot 6$ \\
\hline $\begin{array}{l}\text { HFD } \\
\qquad(n=10)\end{array}$ & $209 \pm 9^{+}$ & $94 \pm 9 *$ & $3 \cdot 75 \pm 0 \cdot 51^{+}$ & $142 \cdot 4 \pm 7 \cdot 3^{+}$ \\
\hline $\begin{array}{c}\mathrm{HFD}+\mathrm{BPS} \\
(n=10)\end{array}$ & $182 \pm 14^{\dagger}$ & $74 \pm 6$ & $4 \cdot 12 \pm 0 \cdot 90^{\dagger}$ & $132 \cdot 8 \pm 6 \cdot 2^{+}$ \\
\hline
\end{tabular}

HFD, high-fat diet; BPS, beraprost sodium; TC, total cholesterol; TG, triglyceride. ${ }^{*} P<0.05$ and ${ }^{\dagger} P<0 \cdot 01$ vs control.

significantly lower in the BPS group compared with the HFD group after $6 \mathrm{~h}$ of fasting, which was not observed after $16 \mathrm{~h}$ of fasting (Table 2). Area under the curves (AUC) also showed improvement of glucose metabolism by BPS treatment (Fig. 1B and D).

\section{BPS reduced adipocyte size}

Histological analysis of epididymal WAT showed that the adipocyte size was increased in the HFD group compared with the control group (Fig. 2A and B). Treatment with BPS reduced adipocyte size (Fig. 2C). Statistical analysis confirmed that BPS significantly reduced adipocyte size (Fig. 2D). These data suggest that BPS enhanced adipocyte differentiation. We therefore examined expression of genes related to adipocyte differentiation. Ppary was significantly suppressed by the HFD, which was reversed by BPS (Fig. 3A). The upregulation of Ppary by BPS showed a borderline significance $(P=0 \cdot 06)$ when three groups were considered. However, the difference between the HFD and BPS groups was statistically significant if only the HFD groups were compared $(P=0 \cdot 02)$. We failed to see a significant effect of $\mathrm{BPS}$ treatment on the expression of $\mathrm{C} / \mathrm{EBP} \alpha$ (Fig. 3B) or adiponectin (Fig. 3C). Although adiponectin mRNA levels were not changed in the three groups, serum adiponectin levels were mildly decreased in the HFD group and BPS groups (Fig. 3D). However, the difference in serum adiponectin levels between the three groups was not statistically significant.

\section{BPS reduced inflammatory changes in WAT in HFD-fed mice}

Chronic inflammation in WAT is a common feature of obesity. Therefore, we examined the infiltration of macrophages into adipose tissue. The number of MAC3-positive macrophage aggregation surrounding adipocytes, often referred to as a crown-like structure (CLS) in WAT (Weisberg et al. 2003, Xu et al. 2003), was significantly increased in the HFD group compared with the control group (Fig. 2E and F; arrowheads). In the control group (Fig. 2E), almost no CLS was observed in WAT. Treatment with BPS significantly decreased the number of CLSs in WAT (Fig. 2G and H). 


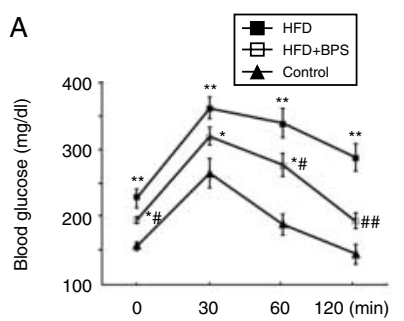

B

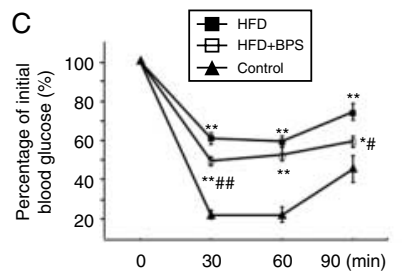

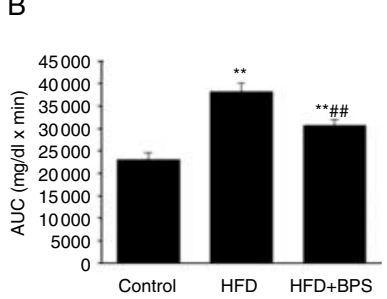

D

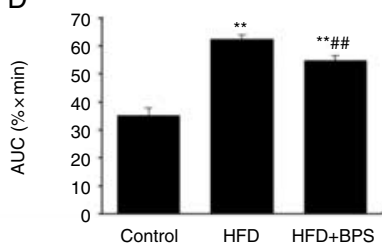

Figure 1 BPS ameliorated HFD-induced insulin resistance. (A) The control group (black triangle) was fed a normal chow and the HFD (black box) and BPS groups (white box) were fed a HFD for 12 weeks. Mice were i.p. injected with $1 \mathrm{~g} / \mathrm{kg}$ glucose and blood glucose levels were measured. (C) Mice were i.p. injected with $0.5 \mathrm{U} / \mathrm{kg}$ insulin and blood glucose levels were measured. (B and D) AUC were calculated. Control group $n=5$, HFD group and BPS group $n=10 .{ }^{*} P<0.05$ and ${ }^{* *} P<0.01$ vs control. ${ }^{*} P<0.05$ vs HFD group, ${ }^{\# \#} P<0 \cdot 01$ vs HFD group.

Real-time PCR analysis showed that HFD-induced expression of TNF- $\alpha$ and MCP1 was significantly suppressed by BPS treatment (Fig. 3E and F). We could not detect serum TNF- $\alpha$ even in mice fed a HFD (data not shown).

\section{BPS attenuated HFD-induced hepatic steatosis}

Finally, we examined whether BPS affects hepatic steatosis induced by the HFD. HFD feeding for 12 weeks caused fatty liver compared with control feeding (Fig. 4A and B). Fat accumulation in the liver was attenuated in the BPS group compared with the HFD group (Fig. 4C and D).

\section{Discussion}

We demonstrated in this study that BPS improved HFDinduced insulin resistance and glucose intolerance. Treatment with BPS reduced expression of inflammatory cytokines, adipocyte size, and macrophage infiltration in WAT of dietinduced obesity mice. BPS also induced modest PPAR $\gamma$ upregulation. Although BPS treatment did not affect serum glucose and insulin levels after 16 h of fasting (Table 2), GTT performed after $6 \mathrm{~h}$ of fasting showed a significant reduction in basal glucose levels in the BPS group. The difference may be ascribed to the length of the fasting period, and prolonged fasting time may attenuate the difference between the HFD group and the BPS group.

Low-grade adipose tissue inflammation is a key state underlying insulin resistance in obesity. An increase in TNF- $\alpha$ mRNA expression was observed in adipose tissue from animal models of obesity and diabetes (Hotamisligil et al. 1993). It has

been suggested that TNF- $\alpha$ is an important mediator of insulin resistance in obesity because neutralization of TNF- $\alpha$ increased peripheral glucose uptake in response to insulin in obese rats. And TNF- $\alpha$-deficient obese mice were protected against obesity-induced attenuation of insulin signaling in muscle and fat tissues (Uysal et al. 1997). Several studies suggest that TNF- $\alpha$ blocks insulin signaling. It is reported that TNF- $\alpha$ inhibits insulin-induced tyrosine phosphorylation and tyrosine kinase activity of the insulin receptor in the obese rat (Hotamisligil et al. 1994a,b). TNF- $\alpha$ activates JNK signaling, and JNK activation promotes the
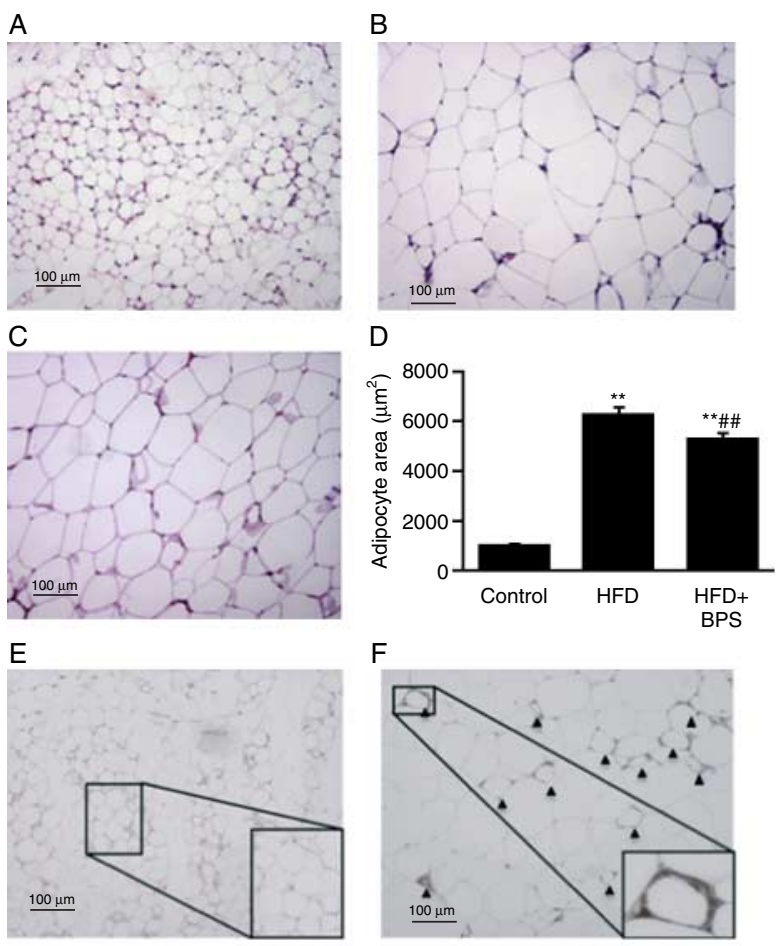

$\mathrm{F}$
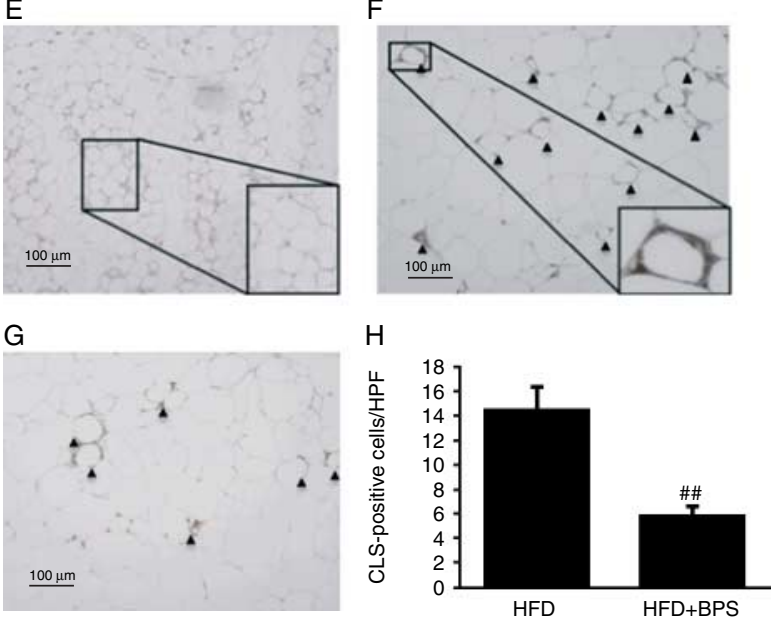

Figure 2 BPS treatment decreased adipocyte size and infiltration of macrophages in WAT. (A, B, and C) Representative microphotographs of $\mathrm{H} \& \mathrm{E}$-stained sections of epididymal WAT from the control group (A), HFD group (B), and BPS group (C) are shown. Scale bar, $100 \mu \mathrm{m}$. (D) Bar graph indicates average adipocyte size of epididymal WAT, $n=5$ (control group; $n=3$ ). ${ }^{* *} P<0 \cdot 01$ vs control. ${ }^{\#} P<0 \cdot 01$ vs HFD group. (E, F, and G) Representative microphotographs of WAT immunohistochemically stained with an anti-MAC3 antibody to stain macrophage in the control group (E), HFD group (F), and BPS group (G) are shown. Scale bar, $100 \mu \mathrm{m}$. (H) Bar graph indicates the number of CLSs in high power field (HPF), $n=7-8$. ${ }^{\# \#} P<0 \cdot 01$ vs HFD group. Almost no CLS was observed in the control group. 

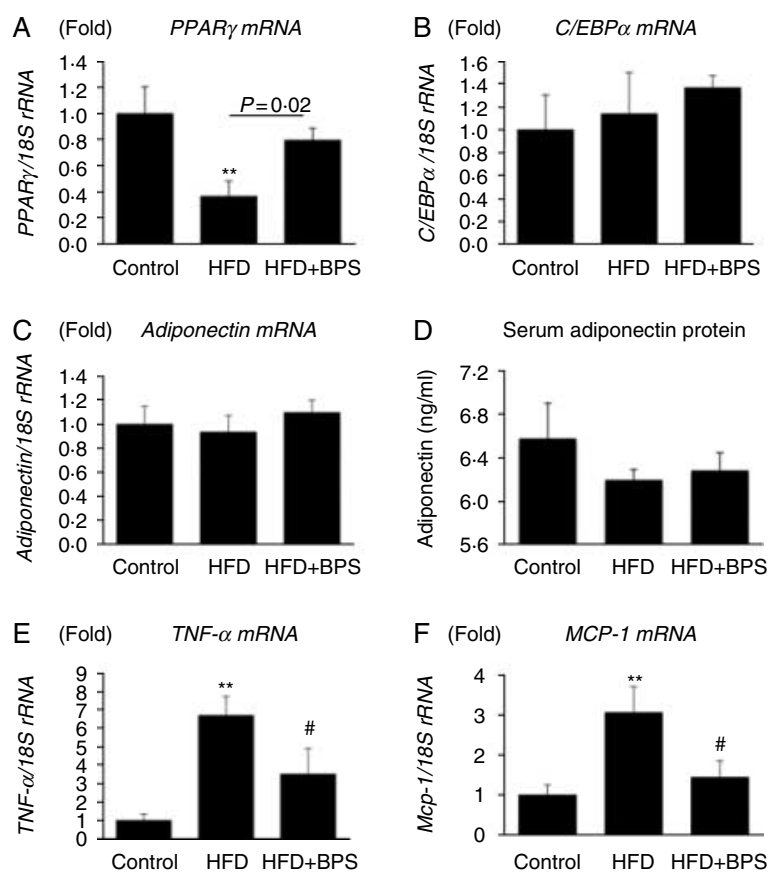

Figure 3 Effect of BPS on the adipocyte differentiation markers in WAT. (A, B and C) The results of real-time qPCR analysis for PPAR $\gamma$ (A), C/EBP $\alpha(\mathrm{B})$, and adiponectin $(\mathrm{C})$ are shown, $n=5$. $* * P<0 \cdot 01 \mathrm{vs}$ control. (D) Serum adiponectin levels were determined by ELISA. (E and F) The results of real-time gPCR analysis for TNF- $\alpha$ (E) and MCP1 (F) expression in WAT are shown, $n=5 .{ }^{* *} P<0 \cdot 01$ vs control. ${ }^{\sharp} P<0 \cdot 05$ vs HFD group.

phosphorylation of IRS1 at serine residues that negatively regulate normal signaling through IRS1 (Aguirre et al. 2000, Shoelson et al. 2006). An absence of JNK1 (MAPK8) improved insulin sensitivity and enhanced insulin receptor signaling in diet-induced obesity mice and $o b / o b$ genetic obesity mice (Hotamisligil et al. 1993, Hirosumi et al. 2002). In this study, BPS reduced mRNA expression of TNF- $\alpha$ in WAT from diet-induced obesity mice. Hence, we assume that reduction of TNF- $\alpha$ may contribute to the improvement of insulin action by BPS, at least in part. It is also expected that the signaling pathways activated by TNF- $\alpha$ are attenuated in the adipose tissue of BPS-treated mice. However, the effect of BPS seems to be multi-fold, such as reduction of MCP1. Therefore, it is difficult to determine specifically whether TNF- $\alpha$-signaling is attenuated in this model. It is important to note that we must be cautious in extrapolating the data in this study to humans because TNF- $\alpha$ neutralizing antibodies have been shown to be ineffective on impacting insulin sensitivity in humans (Ofei et al. 1996).

Several studies showed anti-inflammatory effects of BPS. Ohta et al. (2005) showed that BPS suppressed concanavalin-Ainduced TNF- $\alpha$ and INF- $\gamma$ production and liver injury. It is also reported that BPS prevented the development of cigarette smoke extract-induced emphysema (Chen et al. 2009). Production of TNF- $\alpha$ and interleukin $1 \beta$ (IL $\beta$ ) in the lung

tissue was suppressed by BPS in this model. Although activation of prostacyclin receptor is suggested to be involved in the anti-inflammatory effect, the detailed mechanism of BPS suppression of inflammatory cytokine production is not clear and further study is needed.

Hypertrophied adipose tissue secretes MCP1 (Hotamisligil et al. 1995, Bruun et al. 2005). MCP1 attracts macrophages to adipose tissue (Kamei et al. 2006). It is suggested that infiltrated macrophages secrete MCP1 and proinflammatory cytokines such as TNF- $\alpha$ or IL6, indicating that macrophage infiltration and inflammation of WAT form a vicious circle (Suganami et al. 2005). It is also reported that transgenic overexpression of MCP1 in adipose tissue causes insulin resistance by direct attenuation of insulin signaling in skeletal muscle and liver and inflammation of adipose tissue (Kamei et al. 2006, Kanda et al. 2006). Therefore, MCP1 is thought to contribute to insulin resistance through paracrine and endocrine effects (Kamei et al. 2006). BPS reduced both MCP1 expression and macrophage infiltration, which may contribute to the improvement of glucose tolerance and insulin action.

PPAR $\gamma$ has been known as a master regulator of adipocyte differentiation in vivo and in vitro (Rosen et al. 1999, Camp et al. 2002). PPAR $\gamma$ ligands, such as thiazolidinediones, improve insulin sensitivity by increasing the number of small adipocytes secreting adiponectin and decrease the number of large adipocytes secreting TNF- $\alpha$ in WAT (Okuno et al. 1998, Yamauchi et al. 2001). We observed that treatment with BPS decreased the average size of adipocytes in epididymal WAT from diet-induced obese mice. Although statistical significance was marginal, it is plausible to assume that the increased PPAR $\gamma$ by BPS may contribute to adipocyte

A

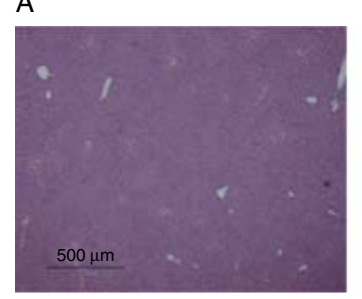

C

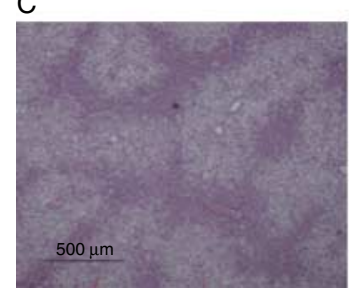

Figure 4 BPS attenuated HFD-induced hepatic steatosis. (A, B and C) Representative microphotographs of H\&E-stained sections of liver from the control group (A), HFD group (B), and BPS group (C) are shown. Scale bar, $500 \mu \mathrm{m}$. (D) Bar graph indicates area of vacuolation, $n=5-8 .{ }^{* *} P<0.01$ vs control. ${ }^{\#} P<0.01$ vs HFD group. 
differentiation and improvement of insulin action. Because PPAR $\gamma$ is known to inhibit NF- $\kappa \mathrm{B}$, a transcription factormediating expression of inflammatory cytokines, BPS may suppress TNF- $\alpha$ and MCP1 expression through PPAR $\gamma$ activation. Although the detailed mechanism of BPS upregulation of PPAR $\gamma$ is not clear, a previous report showed that another prostacyclin analogue, treprostinil, activates PPAR $\gamma$ through prostacyclin receptor-dependent and cAMP-independent mechanisms (Falcetti et al. 2007).

Adipocytes become hypertrophied as obesity progresses. It is suggested that these hypertrophied adipocytes secrete free fatty acid that contributes to fat accumulation in ectopic sites including liver and muscle, leading to the development of insulin resistance (Jacob et al. 1999, Bays et al. 2004, Hwang et al. 2007). Although the mechanism is not clear, BPS mildly decreased serum TC and TG levels (Table 2). A decrease in the serum TC and TG levels by BPS may contribute to the improvement of insulin action.

It is of note that BPS ameliorated hepatic steatosis induced by HFD. Although the precise mechanism is not clear, antiinflammatory effects of BPS may play a role in the attenuation of hepatic steatosis because recent studies suggest that inflammation is one of the critical factors in the development of hepatic steatosis. It was reported that anti-TNF $\alpha$ antibody treatment improved hepatic steatosis in ob/ob mice ( $\mathrm{Li}$ et al. 2003). Treatment with an inhibitor of MCP1 receptor reportedly attenuated insulin resistance and hepatic steatosis in diet-induced obese mice (Tamura et al. 2010). Therefore, reduction of fat accumulation in the liver by BPS treatment may be due to suppression of inflammatory cytokine expression, at least in part, as observed in WAT of the BPS group. However, it is not clear at this point whether cytokine levels in the liver are decreased in the BPS group, and further study is needed.

A recent study showed that BPS improves glucose metabolism in a genetic obesity-induced insulin resistance model (Sato et al. 2010). Although our data mostly agree with those by Sato et al. (2010), our study is also important because we showed beneficial effects of BPS on glucose metabolism in a diet-induced obesity model, which is more clinically relevant than a genetic model. In addition, our data suggest a possible involvement of anti-inflammatory effects of BPS in the improvement of impaired glucose metabolism, which was not obvious in the previous study by Sato et al. (2010).

Taken together, we showed in this study that BPS improved glucose tolerance in mice fed a HFD possibly through suppression of inflammatory cytokines in WAT and induction of adipocyte differentiation. BPS may be beneficial not only for the treatment of patients with peripheral artery disease or pulmonary hypertension but also for treatment of patients with insulin resistance.

\section{Declaration of interest}

The authors declare that there is no conflict of interest that could be perceived as prejudicing the impartiality of the research reported.

\section{Funding}

This work was supported in part by a grant-in-aid for scientific research from the Ministry of Education, Culture, Sports, Science and Technology of Japan (19590867 to T I).

\section{Author contribution statement}

E I researched the data, contributed to discussion, wrote and reviewed/edited the manuscript. T I contributed to discussion and wrote and reviewed/edited the manuscript. K T and K S reviewed/edited the manuscript. H M, T H, J I, and $\mathrm{A} \mathrm{K}$ researched the data.

\section{Acknowledgement}

The authors would like to thank the technical expertise of the Support Center for Education and Research, Kyushu University.

\section{References}

Aguirre V, Uchida T, Yenush L, Davis R \& White MF 2000 The c-Jun $\mathrm{NH}(2)$-terminal kinase promotes insulin resistance during association with insulin receptor substrate-1 and phosphorylation of Ser(307). Journal of Biological Chemistry 275 9047-9054. (doi:10.1074/jbc.275.12.9047)

Bays H, Mandarino L \& DeFronzo R 2004 Role of the adipocyte, free fatty acids, and ectopic fat in pathogenesis of type 2 diabetes mellitus: peroxisomal proliferator-activated receptor agonists provide a rational therapeutic approach. Journal of Clinical Endocrinology and Metabolism 89 463-478. (doi:10.1210/jc.2003-030723)

Bruun JM, Lihn AS, Pedersen SB \& Richelsen B 2005 Monocyte chemoattractant protein-1 release is higher in visceral than subcutaneous human adipose tissue (AT): implication of macrophages resident in the AT. Journal of Clinical Endocrinology and Metabolism 90 2282-2289. (doi:10.1210/ jc.2004-1696)

Camp HS, Ren D \& Leff T 2002 Adipogenesis and fat-cell function in obesity and diabetes. Trends in Molecular Medicine 8 442-447. (doi:10.1016/S14714914(02)02396-1)

Chen Y, Hanaoka M, Chen P, Droma Y, Voelkel NF \& Kubo K 2009 Protective effect of beraprost sodium, a stable prostacyclin analog, in the development of cigarette smoke extract-induced emphysema. American Journal of Physiology. Lung Cellular and Molecular Physiology 296 L648-L656. (doi:10.1152/ajplung.90270.2008)

Falcetti E, Flavell DM, Staels B, Tinker A, Haworth SG \& Clapp LH 2007 IP receptor-dependent activation of PPARgamma by stable prostacyclin analogues. Biochemical and Biophysical Research Communications 360 821-827. (doi:10.1016/j.bbrc.2007.06.135)

Fujiwara K, Nagasaka A, Nagata M, Yamamoto K, Imamura S, Oda N, Sawai Y, Hayakawa N, Suzuki A \& Itoh M 2004 A stable prostacyclin analogue reduces high serum TNF-alpha levels in diabetic patients. Experimental and Clinical Endocrinology \& Diabetes 112 390-394. (doi:10.1055/s-2004-821024)

Goya K, Otsuki M, Xu X \& Kasayama S 2003 Effects of the prostaglandin $I_{2}$ analogue, beraprost sodium, on vascular cell adhesion molecule-1 expression in human vascular endothelial cells and circulating vascular cell adhesion molecule-1 level in patients with type 2 diabetes mellitus. Metabolism 52 192-198. (doi:10.1053/meta.2003.50025)

Hirosumi J, Tuncman G, Chang L, Gorgun CZ, Uysal KT, Maeda K, Karin M \& Hotamisligil GS 2002 A central role for JNK in obesity and insulin resistance. Nature 420 333-336. (doi:10.1038/nature01137)

Hotamisligil GS, Shargill NS \& Spiegelman BM 1993 Adipose expression of tumor necrosis factor-alpha: direct role in obesity-linked insulin resistance. Science 259 87-91. (doi:10.1126/science.7678183) 
Hotamisligil GS, Murray DL, Choy LN \& Spiegelman BM 1994a Tumor necrosis factor alpha inhibits signaling from the insulin receptor. PNAS 91 4854-4858. (doi:10.1073/pnas.91.11.4854)

Hotamisligil GS, Budavari A, Murray D \& Spiegelman BM $1994 b$ Reduced tyrosine kinase activity of the insulin receptor in obesity-diabetes. Central role of tumor necrosis factor-alpha. Journal of Clinical Investigation 94 1543-1549. (doi:10.1172/JCI117495)

Hotamisligil GS, Arner P, Caro JF, Atkinson R \& Spiegelman BM 1995 Increased adipose tissue expression of tumor necrosis factor-alpha in human obesity and insulin resistance. Journal of Clinical Investigation 95 2409-2415. (doi:10.1172/JCI117936)

Hotamisligil GS, Peraldi P, Budavari A, Ellis R, White MF \& Spiegelman BM 1996 IRS-1-mediated inhibition of insulin receptor tyrosine kinase activity in TNF-alpha- and obesity-induced insulin resistance. Science 271 665-668. (doi:10.1126/science.271.5249.665)

Hwang JH, Stein DT, Barzilai N, Cui MH, Tonelli J, Kishore P \& Hawkins M 2007 Increased intrahepatic triglyceride is associated with peripheral insulin resistance: in vivo MR imaging and spectroscopy studies. American Journal of Physiology. Endocrinology and Metabolism 293 E1663-E1669. (doi:10.1152/ ajpendo.00590.2006)

Jacob S, Machann J, Rett K, Brechtel K, Volk A, Renn W, Maerker E, Matthaei S, Schick F, Claussen CD et al. 1999 Association of increased intramyocellular lipid content with insulin resistance in lean nondiabetic offspring of type 2 diabetic subjects. Diabetes 48 1113-1119. (doi:10.2337/ diabetes.48.5.1113)

Kamei N, Tobe K, Suzuki R, Ohsugi M, Watanabe T, Kubota N, Ohtsuka-Kowatari N, Kumagai K, Sakamoto K, Kobayashi M et al. 2006 Overexpression of monocyte chemoattractant protein-1 in adipose tissues causes macrophage recruitment and insulin resistance. Journal of Biological Chemistry 281 26602-26614. (doi:10.1074/jbc. M601284200)

Kanda H, Tateya S, Tamori Y, Kotani K, Hiasa K, Kitazawa R, Kitazawa S, Miyachi H, Maeda S, Egashira K et al. 2006 MCP-1 contributes to macrophage infiltration into adipose tissue, insulin resistance, and hepatic steatosis in obesity. Journal of Clinical Investigation 116 1494-1505. (doi:10.1172/JCI26498)

Li Z, Yang S, Lin H, Huang J, Watkins PA, Moser AB, Desimone C, Song XY \& Diehl AM 2003 Probiotics and antibodies to TNF inhibit inflammatory activity and improve nonalcoholic fatty liver disease. Hepatology 37 343-350. (doi:10.1053/jhep.2003.50048)

Masuzaki H, Paterson J, Shinyama H, Morton NM, Mullins JJ, Seckl JR \& Flier JS 2001 A transgenic model of visceral obesity and the metabolic syndrome. Science 294 2166-2170. (doi:10.1126/science. 1066285)

Ofei F, Hurel S, Newkirk J, Sopwith M \& Taylor R 1996 Effects of an engineered human anti-TNF-alpha antibody (CDP571) on insulin sensitivity and glycemic control in patients with NIDDM. Diabetes $\mathbf{4 5}$ 881-885. (doi:10.2337/diabetes.45.7.881)

Ohta S, Nakamuta M, Fukushima M, Kohjima M, Kotoh K, Enjoji M \& Nawata H 2005 Beraprost sodium, a prostacyclin (PGI) analogue, ameliorates concanavalin A-induced liver injury in mice. Liver International 25 1061-1068. (doi:10.1111/j.1478-3231.2005.01143.x)

Okuno A, Tamemoto H, Tobe K, Ueki K, Mori Y, Iwamoto K, Umesono K, Akanuma Y, Fujiwara T, Horikoshi H et al. 1998 Troglitazone increases the number of small adipocytes without the change of white adipose tissue mass in obese Zucker rats. Journal of Clinical Investigation 101 1354-1361. (doi:10.1172/JCI1235)
Olschewski H, Rose F, Schermuly R, Ghofrani HA, Enke B, Olschewski A \& Seeger W 2004 Prostacyclin and its analogues in the treatment of pulmonary hypertension. Pharmacology \& Therapeutics 102 139-153. (doi:10.1016/j.pharmthera.2004.01.003)

Rosen ED, Sarraf P, Troy AE, Bradwin G, Moore K, Milstone DS, Spiegelman BM \& Mortensen RM 1999 PPAR gamma is required for the differentiation of adipose tissue in vivo and in vitro. Molecular Cell 4 611-617. (doi:10.1016/S1097-2765(00)80211-7)

Sato N, Kaneko M, Tamura M \& Kurumatani H 2010 The prostacyclin analog beraprost sodium ameliorates characteristics of metabolic syndrome in obese Zucker (fatty) rats. Diabetes 59 1092-1100. (doi:10.2337/db09-1432)

Savage DB, Petersen KF \& Shulman GI 2007 Disordered lipid metabolism and the pathogenesis of insulin resistance. Physiological Reviews 87 507-520. (doi:10.1152/physrev.00024.2006)

Shoelson SE, Lee J \& Goldfine AB 2006 Inflammation and insulin resistance. Journal of Clinical Investigation 116 1793-1801. (doi:10.1172/JCI29069)

Suganami T, Nishida J \& Ogawa Y 2005 A paracrine loop between adipocytes and macrophages aggravates inflammatory changes: role of free fatty acids and tumor necrosis factor alpha. Arteriosclerosis, Thrombosis, and Vascular Biology 25 2062-2068. (doi:10.1161/01.ATV.0000183883.72263.13)

Tamura Y, Sugimoto M, Murayama T, Minami M, Nishikaze Y, Ariyasu H, Akamizu T, Kita T, Yokode M \& Arai H 2010 C-C chemokine receptor 2 inhibitor improves diet-induced development of insulin resistance and hepatic steatosis in mice. Journal of Atherosclerosis and Thrombosis 17 219-228. (doi:10.5551/jat.3368)

Uysal KT, Wiesbrock SM, Marino MW \& Hotamisligil GS 1997 Protection from obesity-induced insulin resistance in mice lacking TNF-alpha function. Nature 389 610-614. (doi:10.1038/39335)

Wajchenberg BL 2000 Subcutaneous and visceral adipose tissue: their relation to the metabolic syndrome. Endocrine Reviews 21 697-738. (doi:10.1210/er. 21.6.697)

Watanabe M, Nakashima H, Mochizuki S, Abe Y, Ishimura A, Ito K, Fukushima T, Miyake K, Ogahara S \& Saito T 2009 Amelioration of diabetic nephropathy in OLETF rats by prostaglandin I(2) analog, beraprost sodium. American Journal of Nephrology 30 1-11. (doi:10.1159/000195722)

Weisberg SP, McCann D, Desai M, Rosenbaum M, Leibel RL \& Ferrante AW Jr 2003 Obesity is associated with macrophage accumulation in adipose tissue. Journal of Clinical Investigation 112 1796-1808. (doi:10.1172/JCI19246)

Weisberg SP, Hunter D, Huber R, Lemieux J, Slaymaker S, Vaddi K, Charo I, Leibel RL \& Ferrante AW Jr 2006 CCR 2 modulates inflammatory and metabolic effects of high-fat feeding. Journal of Clinical Investigation 116 115-124. (doi:10.1172/JCI24335)

Xu H, Barnes GT, Yang Q, Tan G, Yang D, Chou CJ, Sole J, Nichols A, Ross JS, Tartaglia LA et al. 2003 Chronic inflammation in fat plays a crucial role in the development of obesity-related insulin resistance. Journal of Clinical Investigation 112 1821-1830. (doi:10.1172/JCI19451)

Yamauchi T, Kamon J, Waki H, Terauchi Y, Kubota N, Hara K, Mori Y, Ide T, Murakami K, Tsuboyama-Kasaoka N et al. 2001 The fat-derived hormone adiponectin reverses insulin resistance associated with both lipoatrophy and obesity. Nature Medicine 7 941-946. (doi:10.1038/90984)

Received in final form 25 March 2012

Accepted 29 March 2012

Made available online as an Accepted Preprint 29 March 2012 